\title{
INEFFABILITY AND NONSENSE
}

\author{
by A. W. Moore and Peter Sullivan
}

\author{
I-A.W. Moore
}

ABSTRACT There are criteria of ineffability whereby, even if the concept of ineffability can never serve to modify truth, it can sometimes (non-trivially) serve to modify other things, specifically understanding. This allows for a reappraisal of the dispute between those who adopt a traditional reading of Wittgenstein's Tractatus and those who adopt the new reading recently championed by Diamond, Conant, and others. By maintaining that what the nonsense in the Tractatus is supposed to convey is ineffable understanding, rather than ineffable truth, we can do considerable justice to each of these readings. We can also do considerable justice to the Tractatus.

D avid Lewis holds that there are inexpressible truths. The following argument, which is a variant of an argument that he discusses, can be used to motivate this view. ${ }^{1}$

Suppose that $S$ is an item that can express a proposition, in the minimal sense that, for some proposition $p$ and for some possible world $w, S$ expresses $p$ in $w$. Say that $S$ univocally expresses proposition $p$ (in possible world $w$ ) if and only if $S$ expresses $p$ (in $w$ ) and $S$ does not express any proposition other than $p$ (in $w$ ). And let $\kappa$ be the number of possible worlds. Now clearly the number of propositions that can be univocally expressed by $S$ is no greater than $\kappa$. But the number of propositions altogether is at least as great as $2^{\kappa}$, the number of sets of possible worlds-perhaps greater, if propositions slice logical space more thinly than sets of possible worlds do. And $2^{\kappa}$ is greater than $\kappa$. Hence there are some propositions that cannot be univocally expressed by $S$.

How does this argument motivate the view that there are inexpressible truths? Well, on the assumption that any truth that can be expressed at all can be univocally expressed by $S$, the argument can readily be converted into an argument for that view. ${ }^{2}$

1. See Lewis (1986), Section 2.3.

2. I am assuming, for these purposes, that a truth is nothing but a true proposition. I am also assuming that there are at least three possible worlds. If there were only two, and if truths sliced logical space no more thinly than sets of possible worlds, then there would be only two truths. 
This does not settle the matter, however. The assumption that any truth that can be expressed at all can be univocally expressed by $S$ is not as innocent as it may appear. It may appear completely innocent. Surely, we may say, if a truth can be expressed at all, then there is a possible world in which, by sheer stipulation perhaps, $S$ expresses it, and in which circumstances elsewhere ensure that $S$ expresses no other proposition, in some other language say. But a little probing of the original argument reminds us that there is at least one proposition that we have independent reason to deny can be univocally expressed by $S$, namely the proposition that $S$ is false. ${ }^{3}$ And if $S$ does in fact express a proposition, but a falsehood rather than a truth-for instance, if $S$ is the sentence 'Grass is pink' - then the proposition that $S$ is false is itself a truth. So it is a truth which, though certainly expressible, cannot be univocally expressed by $S .^{4}$

Lewis himself would accede to this. But he would still regard the original argument as motivating the view that there are inexpressible truths. The point, he would say, is not that there is one special proposition that cannot be univocally expressed by $S$. The point is not even that there is one special family of propositions which, because they involve the semantics of $S$, cannot be univocally expressed by $S$. The point is that there are many more propositions than there are possible worlds. Assuming that $\kappa$ is infinite, only an infinitesimal minority of all propositions can be univocally expressed by $S$. And that, on Lewis's view, has nothing specifically to do with $S$. It is because only an infinitesimal minority of all propositions can be expressed at all. Most are too 'untidy'. In Lewis's own words, they are 'utterly unpatterned and miscellaneous'. 5 Furthermore, of these 'untidy' propositions, half_-if I may so put it_-are truths.

\section{II}

How might we respond either to the original argument or to its use in motivating the view that there inexpressible truths?

\section{See Moore (1984).}

4. Thus it could not be the case both that 'Grass' was a name of the sentence 'Grass is pink' - understood as univocally expressing some proposition - and that '... is pink' denoted falsehoods.

5. Op. cit., p. 108. 
There are all sorts of ways of resisting each. We might reject the very idea of possible worlds as entities fit to be counted; likewise propositions. We might deny that every set of possible worlds determines a proposition. We might challenge the attempt to quantify over all truths. ${ }^{6}$ We might insist that, even apart from any semantic paradoxes, there are limits to what $S$ can express which are not limits to what can be expressed. (The only assumption that has been made so far about $S$ is that it is an item that can express a proposition. On some views this is scarcely an assumption at all. On these views suitable conventions can equip anything to express a proposition. But there are other views whereby nothing can express a proposition unless it has some suitable internal complexity. On these views, in order for an item to express any given proposition it needs, at some relevant level, to share the internal complexity of that proposition. Hence even if we stipulate that the letter ' $G$ ' shall abbreviate the sentence 'Grass is green,' what then expresses the proposition that grass is green is not, so to speak, just the letter but some suitably structured precondition of the very possibility of our making that particular stipulation. $\left.{ }^{7}\right)^{8}$ Another way in which we might respond to the original argument and to the conclusion that there are inexpressible truths would be to accept the conclusion, for the reasons indicated in the argument, and by the standards of expressibility implicit in the argument, but then to try to remove some of the sting from the conclusion by pointing out how high

6. Cf. Sullivan (1999-2000). Not that this, though it certainly helps us resist the original argument, is likely to help us resist the conclusion that there are inexpressible truths.

7. But would there then be an analogue of the original argument, in which the relation of expression was replaced by whatever more complex relation holds, in this example, between the proposition that grass is green and the letter ' $G$ '?

8. It is a nice question, incidentally, to which the discussion below adds some piquancy, how the argument and the conclusion would best be resisted within the framework of Wittgenstein's Tractatus-Wittgenstein (1961), hereafter abbreviated as $T L P$ - according to which 'Man possesses the ability to construct languages capable of expressing every sense': 4.002; cf. 4.5. (In raising this question, I am, of course, prescinding from the nonsensicality of that framework.) At least two of the responses listed above suggest themselves. Thus it could be denied that every set of possible worlds determines a proposition, or, in more Tractarian terms, that every sub-space of logical space is a sense: see 3.4-3.411. Or it could be urged that only what has suitable complexity can express a given truth: see $3.1 \mathrm{ff}$., 3.332 , $3.34 \mathrm{ff}$., and 4.5 ; also relevant is 4.0621 . Note, however, that this latter response would fall prey to the analogue of the original argument mentioned in the previous footnote. 
those standards are. The argument presupposes that for $S$ to express a proposition $p$ is for $S$ to have precisely $p$ as its content. There are lower standards whereby $S$ expresses any proposition that is in some sense 'part' of its content. For instance, there are standards of expressibility whereby the sentence 'Grass is green and coal is black' expresses, among other things, the proposition that grass is green, and indeed the proposition that grass is coloured.

This serves to remind us of something that is basic to the very idea of inexpressibility. There are many different standards of expressibility. These different standards depend on a variety of factors such as: whether expression is restricted to linguistic expression; if so, whether it is restricted to expression in an existing language; or whether it can include expression in a possible language; if the latter, what counts as a possible language; whether, for example, a possible language must be something that a human being could in principle learn; whether it must be something that a human being could in practice learn; whether linguistic expression is confined to the literal; in what sense of 'part', if any, what is expressed can be 'part' of the content of what expresses it (the point just being canvassed); and many more. There is no right or wrong about which of these standards to adopt. Different standards are appropriate for different purposes. $^{9}$

What rationale would there be for adopting standards lower than those implicit in the original argument? One rationale would be the following. If, by whatever good grace, there were a 'complete description' of the world, that is to say a set of true representations that narrowed down to one which possible world it was, still, by the original high standards, we might be forced to say that there were countless truths (consequences of this complete description) that remained unexpressed. That would be bizarre. ${ }^{10}$ Another rationale would be that the most interesting questions about inexpressibility, from a philosophical point of view, are not questions about the awkward carving up of logical space; they are questions about logical space itself. We are all familiar with various kinds of inexpressibility that relate to the

9. Cf. Alston (1956).

10. Lewis (1986), Section 3.2 is relevant here. See also TLP, 4.26. 
former: kinds of inexpressibility whose associated standards of expressibility are relatively high. Most of us have at one time or another found that we cannot express how we feel about something. This may have been because of some deep non-negotiable lack of fit between private sentiment and the public manifestation of it. It may have been because of deficiencies in whatever languages we speak. It may have been because of deficiencies merely in our own vocabularies. It may have been because of practical, social, or psychological impediments to our using even the linguistic resources available to us. But it has not been because of the kind of inexpressibility by which philosophers are typically exercised, or at least by which some of them like to think that they are exercised: inexpressibility that has to do not with how things are but with their being any way at all; inexpressibility whose associated standards of expressibility are low enough to make it (the inexpressibility) a matter of the deepest principle. ${ }^{11}$

To repeat: there is no right or wrong about which standards to adopt. But it will be as well for me to settle on some standards and to give some indication of what they are before I proceed.

Now roughly, I intend my discussion to be based on the lowest standards of expressibility consonant with its retaining the sort of philosophical interest to which I have just adverted. It is important, however, that these are not the lowest standards there are. In particular, I shall discount all but linguistic expression. For example, I shall discount expression by means of music. I shall also discount expression of what is not itself either true or false. For example, I shall discount expression of moods. A little more precisely, I shall define expression in the following way:

$x$ expresses $y$ if and only if (i) $x$ is a linguistic item with content that makes it either true or false, (ii) $y$ is a non-linguistic item ${ }^{12}$ with content that makes it either true or false, and (iii) the content of $x$ entails the content of $y{ }^{13}$

I shall also allow for a derivative sense in which people can express things: a person $A$ expresses an item $y$, in this derivative

11. Cf. Wittgenstein (1974), Pt I, Section 610; Wittgenstein (1980), p. 16, fourth paragraph; and Cooper (1991).

12. This is not to preclude the possibility that, as in the case of certain complex beliefs, $y$ depends for its existence on language.

13. Thus the sentence 'Grass is green and coal is black' expresses, among other things, my belief that grass is green. 
sense, if and only if $A$ produces an item $x$ that expresses $y$ in the defined sense. ${ }^{14}$ I shall otherwise adopt the lowest standards of expressibility I can. ${ }^{15}$ And I shall reserve the label 'effability' for expressibility by these standards - as I shall, mutatis mutandis, its cognates 'effable', 'ineffable', and the rest.

\section{III}

Very well; are there, in these terms, any ineffable truths?

I am convinced that there are not. ${ }^{16}$ But I shall not try to argue for that conclusion here. ${ }^{17}$

Actually, I am tempted to say that it does not need much in the way of argument. I find myself in the same sort of position vis-à-vis the question whether there are any ineffable truths as Donald Davidson does vis-à-vis a similar question that he poses in his celebrated essay on the idea of a conceptual scheme: ${ }^{18}$ whether there could be a language whose sentences were untranslatable into any of ours. 'It is tempting,' Davidson writes, 'to take a very short line indeed: nothing, it may be said, could count as evidence that some form of activity could not be interpreted in our language that was not at the same time evidence that that form of activity was not speech behaviour. ${ }^{19}$ He proceeds to make clear that the only thing wrong with this short line would be its shortness, not, so to speak, its direction. At a key moment later in

14. Thus you can express my belief that grass is green by saying, 'Grass is green and coal is black.'

15. Note that, by these standards, it is no obstacle to the expressibility of a truth that, if it were expressed, it would be a falsehood. Thus the thesis that all truths are expressible (by these standards), whatever else might be said against it, does not yield the conclusion that all truths are expressed in the way in which the thesis that all truths are knowable notoriously yields the conclusion that all truths are known: see Fitch (1963).

16. Or at least, with the possible exception of necessary truths, which may be said to lack content, I am convinced that there are not. The idea that necessary truths lack content is of a piece with the idea embraced in TLP that necessary truths lack sense: see 4.46-4.461 and cf. 3.13. For current purposes I do not need to go into detail about how I understand 'content'. I can accordingly leave this matter unsettled. (But note: if I were to accede to a conception of content that was sufficiently demanding for necessary truths to lack it, then I should likewise have to accede to the paradox of ineffable truths that can be put into words, for instance the truth that all aunts are female. This paradox would at worst, I think, reflect idiosyncrasy in my use of 'ineffable'.) I shall ignore this complication throughout the main text.

17. For a sketch of an argument see Moore (2003), Section II.

18. Davidson (1984).

19. Ibid., p. 185. 
the essay he addresses the following subsidiary question: 'How well [do] we understand the notion of truth, as applied to language, independent of the notion of translation [?] ${ }^{20}$ And his answer, which he goes on to elaborate, is a virtual re-appropriation of the short line: 'We do not understand it independently at all., 21

Similarly, I am inclined to say that we do not understand the notion of truth, at least when it is taken in its strictest sense, independently of what can be expressed; or rather, more cautiously, that we do not understand the notion of $a$ truth independently of that. (The individuation involved in talking about $a$ truth, by forcing the question of where one truth stops and another begins, clearly puts additional demands on talk in general about truth.) ${ }^{22}$ But I concede that there is much more to be said. ${ }^{23}$ The reason I shall not try to say any of it now is that my chief concerns lie elsewhere. And this in turn connects with the fact, whose relevance will be clear later, that the idea of an ineffable truth is quite foreign to Wittgenstein's Tractatus. ${ }^{24}$

\section{IV}

Suppose we accept, then, that there are no ineffable truths; and likewise, no ineffable falsehoods. Does this mean, given my criteria of expression, that there can be no further interest in the question whether anything is ineffable? I do not think so.

Most things, of course, since they clearly do not have content that makes them either true or false, are trivially ineffable. Ineffability, on my understanding, is not the same as indescribability. A sock, for example, is ineffable, even if we can give a complete description of it. So too, for that matter, is the opening bar of Beethoven's fifth symphony - which gives the lie to Ramsey's famous quip about our not being able to whistle what we cannot

20. Ibid., p. 194.

21. Ibid.

22. Cf. Kremer (2001), p. 61.

23. For some relevant observations, which include further scepticism about the idea of an ineffable truth, see Horwich (1990), Ch. 2, fn. 4; Quine (1992), pp. 77 ff.; and Wright (1992), pp. 72-73.

24. See above, fn. 8. Cf. also TLP, 4.063. (Note: on a conception of content whereby the Tractatus is committed to the ineffability of necessary truths - see above, fn. 16then what is foreign to it is not, of course, the idea of an ineffable truth, but the idea of a truth that cannot be put into words.) 
say (at least on one uncharitably literal interpretation of that quip). ${ }^{25}$ The issue is whether there are things whose ineffability is not trivial in this way. Are there perhaps things which, though ineffable, are of such a sort that we might have expected them to be effable, say because most things of that sort are?

I believe so. I have urged elsewhere that certain states of knowledge fit the bill. ${ }^{26}$

What I had in mind included some (but by no means all) states of knowing how to do something: for instance, states of knowing how to exercise a given concept. However, Jason Stanley and Timothy Williamson have recently defended a view that constitutes a challenge to this idea. This is the view that 'knowledgehow is simply a species of knowledge-that. ${ }^{, 27}$

Consider a standard case: say, Ellen's knowledge of how to play the violin. On Stanley's and Williamson's view, there is some suitable way for Ellen to play the violin such that what she knows is that this is a way for her to play the violin. And that makes her knowledge effable. One way to express it would be: first, to get Ellen to play the violin; then to draw attention to the way in which she does so; and then to say, 'This is a way for Ellen to play the violin.' ${ }^{28}$

I agree with very much of what Stanley and Williamson say. ${ }^{29}$

25. Ramsey's quip is 'What we can't say we can't say, and we can't whistle it either': Ramsey (1931), p. 238. Ramsey is alluding to TLP, 7. He is also, as Hacker points out in Hacker (2000), fn. 5, alluding to Wittgenstein's well-known expertise in whistling.

26. Moore (1997), Ch. 8.

27. Stanley and Williamson (2001), p. 411.

28. Admittedly, this would not display the precise modes of presentation involved in her knowledge. Thus suppose Ellen had not known how to play the violin, but had been shown someone else playing the violin in that way and had been told, 'This is a way for you to play the violin.' She would then have had knowledge - different knowledgewhich could have been expressed in the same way: see Stanley and Williamson (2001), pp. 428-429. And the difference here is, precisely, a difference in mode of presentation. But this merely illustrates how low my standards of expressibility are. By these low standards, we should likewise have to say that, if Ellen woke up one day oblivious of who she was but aware that she was lying in hospital, her knowledge could be expressed by saying, 'Ellen is lying in hospital': cf. Moore (1997), p. 197.

29. I am gratified to find several echoes of their argument in my own argument for the view that nothing in the semantics of the phrase 'knows how to' provides ready proof of the existence of ineffable knowledge: see Moore (1997), Ch. 8, Section 1. This is why I cannot resist the following captious response to their claim, in op.cit., fn. 47, that I use 'the alleged distinction [between knowledge-how and knowledgethat] to argue that there is ineffable knowledge'. I would say rather that I argue (independently) that there is ineffable knowledge, (some of) which I identify as 'knowledge-how'. 
Certainly I think they show their view to be, as they put it, "the default position'. ${ }^{30}$ I am not persuaded, however, that there are no overriding considerations. ${ }^{31}$ And although I cannot mount a full defence of my own opposed view here, I shall try to do a little to motivate it.

To this end, rather than give a direct reason for denying that 'knowledge-how' is a species of 'knowledge-that', ${ }^{32}$ I shall mention a related case, which I think makes similar trouble for Stanley's and Williamson's view. Consider my knowledge of what it is for an object to be green. On their view this is knowledge, concerning something, that that thing is what it is for an object to be green. But concerning what? A simple reply would be: 'What it is for an object to be green.' But what kind of thing is that? If I try to express my knowledge by indicating a green object and saying, 'This is what it is for an object to be green,' what can I be referring to by 'this'? There does not seem to me to be any good answer. Nothing short of an unacceptable Platonism, it seems to me, can subserve the extension of their account to this case. ${ }^{33}$ I do not think that my knowledge of what it is for an object to be green is knowledge that anything is the case. Nor, crucially, do I think that it is effable. ${ }^{34}$

\section{Op. cit., p. 431.}

31. For that matter, I am not persuaded that, even if their view is correct, it tells decisively against the possibility of ineffable knowledge. For even if 'knowledge-how' $i s$ a species of 'knowledge-that', some 'knowledge-how' may be ineffable because some 'knowledge-that' may be ineffable. (I was too quick to dismiss this possibility in Moore (1997): see Ch. 8, Appendix.) Here I am simply echoing the point that I made in fn. 16, that some truths may be ineffable: necessary truths. Thus consider my knowledge of how to exercise the concept of greenness. And suppose, with Stanley and Williamson, that this is knowledge, concerning some way to exercise the concept of greenness, that it is a way to exercise the concept of greenness. Then it is knowledge (presumably) of what could not be otherwise. So it may be said to lack content, in which case, by my criteria of expression, nothing is to count as expressing it. (Cf. the Tractarian idea that 'thoughts' must have sense, which means that when, for example, I know that it is either raining or not raining - this example is borrowed from $T L P$, 4.461-my knowledge does not count as a thought: see ibid., 2.225-3, 3.13, 4, and 5.1362. This would accord very well with my own general conception of these matters, whereby knowledge is ineffable when it has nothing 'to answer to': see Moore (1997), Ch. 8, Section 3.)

32. This is done in Schiffer (2002) and Koethe (2002).

33. Cf. Moore (1997), pp. 134-135.

34. Cf. Wittgenstein (1974), Pt I, Sections 75, 78, and 610. Note: this forces me to retract the claim I make about finite verbs in Moore (1997), p. 168. I would now modify that claim by adding 'typically'. 


\section{V}

But suppose I am wrong about the existence of ineffable knowledge. Are there any other candidates for the title of non-trivial ineffability? I think there are. I have in mind certain states of understanding. ${ }^{35}$ It is clear that many states of understanding are effable; an example would be a solicitor's understanding of some legal nicety that she has to explain to her clients. But it is far from clear that they all are.

The case of understanding has a particular significance in view of how much attention has recently been devoted to Wittgenstein's remark, in the penultimate section of the Tractatus:

Anyone who understands me eventually recognizes [my propositions] as nonsensical. ${ }^{36}$

This remark appears to be part of the 'frame' of the book, in which Wittgenstein intends to make a straightforwardly true claim about the nonsense that constitutes the bulk of the book inside that 'frame'. He avoids paradox precisely by casting himself as the intended object of understanding, rather than the nonsense, which of course cannot be understood. ${ }^{37} \mathrm{He}$ goes on to connect understanding him in this way with 'seeing the world aright' ${ }^{38}$ And this in turn suggests that, whatever else is going on in this deeply puzzling work, it is part of the design of the project that the reader who successfully grapples with it should be in some sense better off than he would have been had he not done so. ${ }^{39}$

35. In fact I think that states of understanding are states of knowledge. However, I would relinquish this if it could be shown that there was no room for ineffable knowledge. I would rather leave room for ineffable understanding. See Moore (1997), pp. 161 and $183 \mathrm{ff}$.

36. TLP, 6.54 . Note that Wittgenstein's use of the term 'proposition' is different from mine in Sections I and II of this essay. I was using 'proposition' in something more like the way in which Wittgenstein uses 'possible situation'-e.g. ibid., 2.202or 'sense' - e.g. ibid, 2.221.

37. See e.g. Conant (1991), p. 159; Conant (2000), p. 198; and Diamond (2000), pp. $150-151$.

38. $T L P, 6.54$.

39. But note that even this seemingly cautious formulation runs into some difficulties in view of the very first sentence of the preface to the book. (Those who see the book as having a 'frame' typically reckon the preface as part of the 'frame': see e.g. Conant (1991), p. 159, and Diamond (2000), p. 149.) The sentence in question reads, 'Perhaps this book will be understood only by someone who has himself already had the thoughts that are expressed in it ... ': TLP, p. 3, my emphasis. (My concern here is with the word 'already'. But of course, there is also a problem attaching to 'the thoughts that are expressed in it', which sits ill with the idea that the bulk of the 
The idea that the Tractatus has a 'frame', in which Wittgenstein at once dissociates himself from the rest of the book and proclaims the benefits of properly engaging with the rest of the book, finds particular favour with (and is particularly associated with) those who adopt the new reading of the Tractatus recently championed by Cora Diamond, James Conant, and others. This reading is pitted against what I shall call the traditional reading. On the traditional reading:

The Tractatus consists mostly of nonsense because what Wittgenstein is trying to convey, about language and its limits, is, by its own lights, ineffable. The only way in which he can convey itthe only way in which he can get the reader to 'see the world aright' - is by dint of a special kind of nonsense: what we might call 'illuminating' nonsense. ${ }^{40}$

\section{On the new reading:}

There is nothing ineffable. There is only the temptation to see sense where it is lacking. Wittgenstein's aim is therapeutic. The book consists mostly of nonsense because he is trying, by indulging this temptation, to eliminate it; by producing nonsense that appears to have sense, and then testing the appearance, to get the reader to acknowledge the illusion, so that the temptation disappears, and the reader is left realizing that the nonsense is precisely that: sheer lack of sense, which conveys nothing whatsoever. ${ }^{41}$

These readings look as if they could scarcely be further apart. But two things should be noted straight away. First, even on the traditional reading, there is no reason why we should not be left realizing that the nonsense in the book is sheer lack of sense; in other words, that what makes it nonsense is simply that Wittgenstein has 'failed to give a meaning to certain signs in his propositions' ${ }^{42}$ (He could have stipulated, for instance, that he was using 'object' to mean 'emerald' and 'simple' to mean 'green'. Had he done so, then 2.02 - 'Objects are simple'-would not have been nonsense. It would have been true. As it stands,

book consists of nonsense.) For some comments relating to the tension between this sentence and what I say in the main text see Friedlander (2001), pp. $155 \mathrm{ff}$. See also Conant (1989), pp. 245-246.

40. This is Hacker's term: see Hacker (1986), p. 18.

41. See e.g.: Diamond (1991); Diamond (2000); Conant (1989); Conant (1991); Conant (2000); Witherspoon (2000); and Kremer (2001). For a powerful recoil in favour of the traditional reading see Hacker (2000). Poised somewhere in between are Reid (1998); McGinn (1999); Proops (2001); and Sullivan (2002).

42. Here I am alluding to $T L P, 6.53$. The key relevant sections of the book, of which the traditional reading can take just as much note as the new reading, are $5.473 \mathrm{ff}$. 
it is of a piece with 'Omples are sibject.') Secondly, even on the new reading, the nonsense in the book is supposed to serve a function. We are supposed to 'see the world aright' as a result of processing this nonsense. So it is not like the nonsense that a monkey at a typewriter might have produced. It has been carefully crafted to have certain effects on those who understand the language. ${ }^{43}$ (We do well to remember in this connection how exercised proponents of the new reading sometimes get, without any intimation of irony, about the best way to translate parts of this nonsense. ${ }^{44}$ ) Once we have taken due account of these two things, and once we have taken due account of the possibility of ineffable understanding, there are ways of construing the two readings whereby, to borrow a wonderful phrase of David Wiggins's from a different context, 'Suddenly it seems that what makes the difference between [them] has the width of a knifeedge. ${ }^{45}$ The point is this. In overlooking the possibility that things other than truths are non-trivially ineffable, ${ }^{46}$ we are

43. As Diamond says, Wittgenstein holds that the nonsense he has produced 'may be useful or even for a time essential': Diamond (1991), p. 181. Cf. Diamond (2000), pp. 158-159. (Hacker fastens on this in Hacker (2000), pp. 361-362, though, rather unfairly in my view, he ridicules the idea that the presence of such nonsense in a text can be adduced in support of any interpretation of that text.)

44. E.g. Witherspoon (2000), fn. 13; cf. also Conant (2000), fns. 4 and 81. Not that this is a criticism. The idea of translating nonsense is not the absurdity it may sound, as witness the existence of French and German translations of Lewis Carroll's famous nonsense-poem 'Jabberwocky' (see Hofstadter (1980), pp. 366-368 and 372-373 for references and discussion). The matter is further complicated by Conant's suggestion that which parts of the Tractatus count as nonsense may depend partly on the reader: see Conant (2000), fn. 102.

45. Wiggins (1995), pp. 327-328.

46. There is certainly a tendency, on both sides of the debate initiated by this new reading, to do precisely that. E.g. consider this: '[Wittgenstein] did think that one can mean something that cannot be said ... [For example,] what the solipsist means is quite correct; only it cannot be said, but it makes itself manifest (Tractatus, 5.62) ... So there are, according to the author of the Tractatus, ineffable truths that can be apprehended': this is from Hacker (2000), p. 368, his emphasis. And consider this: 'The proponents of the [traditional reading of the Tractatus] ... see that the sentences they are attracted to are nonsense, but they still want to hold onto what (they imagine) the nonsense is trying to say. They conclude that [the Tractatus must convey] ... an "insight" into the truth of certain deep matters - even though, strictly speaking, this truth cannot be put into language. [But they are wrong.] Wittgenstein's aim is to enable us to recognize that there is no ineffable "it" ...': this is from Conant (1991), p. 160, his emphasis, some emphasis removed. (I have inserted the sentence 'But they are wrong' to make clear, what quoting this passage out of context would otherwise have made unclear, that the next sentence is asserted in propria persona.) For awareness of the possibility which I am saying tends to be overlooked see: Kremer (2001), Section IX, in which I find a great deal of pleasing convergence with my own thinking 
bound to see the two readings are irreconcilably differing about whether Wittgenstein believes there $i$ s anything (any truth) that is ineffable. But once we register that the state that we are supposed to get into, the state of understanding Wittgenstein, may itself be ineffable, then we can see the two readings quite differently. Where the traditional reading holds that, for Wittgenstein, the nonsense in the Tractatus conveys 'something' ineffable, we can construe this occurrence of 'something' as embracing just such understanding. And where the new reading holds that, for Wittgenstein, the nonsense in the Tractatus conveys 'nothing', and 'nothing' is ineffable, we can construe these occurrences of 'nothing' as restricted in their range to truths. We can then look back at the sketches of the two readings proffered above and see each as entirely consonant with the other.

I should emphasize, however, that I am not, in saying this, claiming to do full justice to the intentions of all those who advocate either of these readings. To claim that would be crazy. Perhaps what I have done is something more like what Marie McGinn does in a recent essay, where she proposes a third reading that is intended to retain the advantages of each of these two. ${ }^{47}$ She says that these two readings 'offer us the unappealing alternative between reading Wittgenstein's remarks as nonsense that conveys ineffable truths about the world and as nonsense that conveys nothing whatsoever'. ${ }^{48}$ She then advances her own reading, which is designed to enable us to escape this choice. ${ }^{49}$ But whether any such third reading is a genuine alternative to each of the original pair or something more like a charitable reconstruction of each of them or (least plausibly, I suppose) a compendium of what each of them actually comes to, I am certain that it deserves our serious attention.

\section{VI}

Of course, this is no kind of vindication of Wittgenstein unless the idea of ineffable understanding itself deserves our serious

about these matters; Proops (2001), pp. 378 ff., in which, however, the possibility is not always carefully enough distinguished for my liking; and Sullivan (2002), Section 2.4. See also McGinn (1999), about which I shall have more to say shortly.

47. McGinn (1999): see esp. pp. 496-497. There is much in this essay with which I am sympathetic. There is even more that I admire.

48. Ibid., p. 498.

49. See the summary of her position in ibid., pp. 512-513. 
attention. All that I have done so far is to advert to the possibility of such a thing. I cannot, in these confines, do much more. But in the three remaining sections of this essay I should like to deflect one natural objection to the idea, and then say a little more about how the idea relates to the Tractatus.

The objection is an echo of an objection to the Lewisian idea of inexpressible truth with which we began. If, in fact, there is such a thing as ineffable understanding, the standards of effability that allow this fact to be so described make it (the fact) appear much more noteworthy than it really is. These standards, though relatively low, are still high enough for a state of understanding to count as ineffable just because it does not have content that makes it either true or false; or just because the best attempt to express it issues in something that does not have content that makes it either true or false. If these standards are relaxed, that is if the corresponding criteria of expression are relaxed, and if Wittgenstein's aim in writing the Tractatus is realized, then we are at perfect liberty to say the following: that Wittgenstein's understanding of language and its limits, and the reader's eventual understanding of him, which is in effect the reader's eventual shared understanding of language and its limits, are all expressed in the book. Moreover, if our standards of meaningfulness are similarly relaxed, we are also at liberty to say that the sentences in the book are, for that very reason, meaningful. Indeed, if we think that Wittgenstein, in writing the Tractatus, intends his sentences to produce some particular effect in the reader by means of the recognition of this very intention, then we do not have to be all that Gricean ${ }^{50}$ to think that this just is the kind of thing that we ordinarily mean by (non-natural) meaning. And if the effect in question is partly that the reader should recognize Wittgenstein's sentences as lacking meaning, then this gives an ironical twist to the accusation of self-stultification that is ordinarily levelled at Wittgenstein. The accusation of self-stultification that is ordinarily levelled at Wittgenstein is that his work subverts itself in such a way that he does not in the end mean anything by it. It now appears that, on the contrary, his work subverts itself in such a way that he does in the end mean something by it! ${ }^{51}$

\section{See Grice (1967).}

51. As Wittgenstein himself observes, 'If everything behaves as if a sign had meaning, then it does have meaning'; TLP, 3.328. 
I have two comments to make in response to this objection. First, concerning this last point, it is not clear that Wittgenstein does intend his sentences to produce some particular effect in the reader 'by means of the recognition of this very intention'. Does he not rather intend his sentences to produce their effect by means of the reader's ultimate failure, in trying to construe them as the network of truth-evaluable statements that they appear to be, to make anything of them?

The second comment is that the objection can in any case be, at most, an objection to the terminology. Perhaps it is misleading to apply the word 'ineffable' to whatever does not have content that makes it either true or false. ${ }^{52}$ But the concept for which the word has been reserved is impervious to this objection. The concept is simply what it is. Nothing in the concept is intended, or would be able, to abnegate the myriad effects that a text can have on a reader, or the myriad uses to which words can be put, or the myriad ways in which a person can share his or her understanding with another person.

\section{VII}

How then does the idea of ineffable understanding relate to the Tractatus? Is it an acceptable reading of the book to say that what it is supposed to subserve, namely understanding of Wittgenstein, is a case in point?

Well, there is at least this much to be said for the reading. If there is such a thing as understanding Wittgenstein via the Tractatus, in the way that he intends, then any attempt to express this understanding (as opposed merely to talking about it) is liable to issue in the same kind of nonsense: 'A picture cannot depict its pictorial form,' 'Value lies outside the world,' et cetera. ${ }^{54}$ And if it really is impossible to do any better than this, when attempting

52. It would certainly be highly unorthodox to apply the word to my knowledge that aunts are female: see above, fns. 16 and 31 .

53. Here it is worth remembering the context in the Tractatus in which Wittgenstein makes the following important claim: 'In philosophy the question, "What do we actually use this word or this proposition for?" repeatedly leads to valuable insights.' He does so when discussing our use of mathematical 'propositions', which in his view are really pseudo-propositions, nonsense just like the bulk of his own book: TLP, 6.211. (For the idea that mathematics consists of nonsense see ibid., 6.2; see also 5.533-5.534.) A passage from Wittgenstein's later work that is very pertinent here is Wittgenstein (1974), Pt I, Sections 498-499.

54. These two examples are derived from $T L P, 2.172$ and 6.41 respectively. 
to express the understanding, then it follows that the understanding cannot be expressed.

But is this all that we can say about the understanding that is supposed to accrue from reading his book: that the closest we can get to expressing it is producing nonsense of the very kind we find in the book? If it is, that must make us feel uneasy. And we shall not feel much easier if all we can add to this is that such understanding includes a capacity to recognize the resultant nonsense as nonsense. This is too reminiscent of the sign which reads 'Mind the plinth' and which is on a plinth whose sole purpose is to support it.

In fact, however, we can say more. If there is such a thing as understanding Wittgenstein via the Tractatus, in the way that he intends, then it includes a capacity to recognize as nonsense not only the nonsense in the Tractatus, but other, similar 'transcendental twaddle'. ${ }^{55}$ It includes a capacity, 'whenever someone ... [wants] to say something metaphysical, to demonstrate to him that he [has] failed to give a meaning to certain signs in his propositions'. ${ }^{56}$

Nor should the significance of this be underestimated. For Wittgenstein, just as for Kant, our susceptibility to illusions of sense is as deep as our susceptibility to sense itself. It is almost as hard to imagine the latter without the former as it is to imagine the former without the latter. ${ }^{57}$ This means that our grasp of concepts comes to have two aspects. Alongside our knowledge of how to use them, there is our knowledge of how not to use them; alongside our command of what sense they can be used to make, there is our command of what ostensible sense they can be used to make. Each of these admits of degrees. Our command

55. This phrase is Wittgenstein's own: see Hacker (1986), p. 104.

56. TLP, 6.53; cf. 4.003. Cf. also McGinn (1999), pp. 502 ff.

57. TLP 4.002. (Cf. Wittgenstein (1974), Pt I, Section 111 and the material from 'Big Typescript' to which Hacker refers in Hacker (1996), pp. 112-113.) Kant would go further. He would say that we can no more free ourselves of such illusions than we can prevent the moon from appearing larger to us when it is nearer the horizon: see Kant (1998), A297-298/B354-355. This is because, on Kant's view, we have an ineliminable urge to transcend the very limitations that enable us to make sense of things in the first place: see ibid., Avii-viii and A642/B670. Cf. Cavell (1979), p. 109, where he writes, 'Nothing is more human than the wish to deny one's humanity,' a theme adopted by Weiss in Weiss (2001). Cf. also what I call 'our aspiration to be infinite', in Moore (1997), Ch. 11. 
in the latter case can be more or less complete, just as our command in the former case can. Some illusions of sense are very superficial indeed ('The square root of 2 is green'); some, a bit deeper ('It is five o'clock on the sun' ${ }^{58}$ ); some, deep enough that a little reflection is needed to carry conviction that they are illusions of sense at all ('It is five o'clock at the North Pole'); some, so deep that it can be a matter of unresolved controversy whether that is what they are ('I have performed infinitely many tasks $\left.{ }^{, 59}\right) .^{60}$ The depth of some of these illusions means that making sense includes, for us, a continual struggle against merely seeming to make sense and against the perplexity that merely seeming to make sense can cause. For instance, although each of us knows what it is for something to be green, this is partial knowledge, and, at least in as much as we are prone to philosophical reflection, it is constantly having to be re-earned against the lure of certain incoherent pictures of what it is for something to be green: most notably, against the lure of the kind of transcendental idealism that we find in the Tractatus, whereby what it is for something to be green is for that thing's greenness to be part of 'my' world - if not to be part of 'me' ${ }^{61}$ It follows that the capacity to recognize 'transcendental twaddle' for what it is, which is part of the understanding that is supposed to accrue from reading the Tractatus, is, for us, a precondition of the very capacity to make sense.

But can we say some more about such understanding, and in particular about why it is ineffable?

58. This example is taken from Wittgenstein (1974), Pt I, Section 350.

59. See Moore (1989-90).

60. Note: these examples, consisting as they do of solitary sentences, should not be allowed to obscure how context-dependent the making of sense is. For each of these sentences we can imagine a context in which, even without special stipulation, an application of that sentence would make sense. But I am thinking of applications of them in more standard contexts. (See further Mackie (1981) and Angene (1982): I side with Angene.) Note also: the contextual factors that determine whether an application of a sentence makes sense may include the applications of other sentences, some of which purport to be consequences of it and some of which purport to have it as a consequence. This means that, whenever a fairly complex text contains some nonsense, there is liable to be a radical indeterminacy about precisely where the nonsense is to be located. In particular this is true of the Tractatus. See again Conant (2000), fn. 102, cited above in fn. 44.

61. See TLP, 1.1, 5.62, and 5.63-according to which, respectively, 'The world is the totality of facts, 'The world is $m y$ world,' and 'I am my world,' Wittgenstein's emphasis. Cf. also Kant (1998), A129. I try to say some more about the lure of transcendental idealism in Moore (1997), Chs. 6-9. 


\section{VIII}

Consider this. On the austere view of nonsense which is fostered by the Tractatus, and which, to the best of my knowledge, is endorsed by all those who adopt the new reading, nonsense is only ever sheer lack of sense. ${ }^{62}$ On this view, the judgement that something is nonsense is always a judgement about the actual history, to date, of some particular sign ('No meaning has so far been given to this sign'). Such a judgement is always empirical, provisional, and metalinguistic. However, the discussion above suggests that the judgement that something is nonsense is sometimes none of these things. It suggests that the judgement is sometimes arrived at by reflection on concepts; and that it is therefore most appropriately expressed by using, not mentioning, the corresponding signs ('There is no such thing as its being five o'clock at the North Pole'). Does this mean that the austere view must be rejected?

I do not think so. I think the claim that something is nonsense is always empirical, provisional, and metalinguistic. The semantics and rules of a language can determine what makes sense. They cannot, except by default, determine what fails to make sense. It is true that the rules of a language can proscribe as well as prescribe. But the proscriptions are so to speak boundary marks for the prescriptions. They register where the prescriptions cease to have application. Thus there are rules determining what the time is at different points on the surface of the earth for each of the earth's orientations with respect to the sun; and, as far as these go, no meaning attaches to the sentence 'It is five o'clock at the North Pole.' So there is a sense in which, as far as these rules go, we are not allowed to say that. Anyone intending to apply these rules who does say that is rather like someone intending to play chess who moves his rook diagonally. We can say that such a person has made an illegal move. But we can also say that such a person has failed to make any move at all. An illegal move is not a special kind of move. It is as if he has poured coffee all over the board. ${ }^{63}$ And whether what he has done constitutes a move in any other actual game is a matter of brute fact. The judgement that it does not is an empirical, provisional judgement about what games there are.

62. See again $T L P, 5.473 \mathrm{ff}$., to which I referred in fn. 42.

63. Cf. in this connection Wittgenstein (1974), Pt I, Section 500. 
The point, however, is this. Whether what he has done constitutes a move in chess, which is what he intends, is not a matter of brute fact. That is determined by the rules of chess. ${ }^{64}$ Likewise, whether any meaning attaches to the sentence 'It is five o'clock at the North Pole,' as far as our ordinary chronometry goes, is not a matter of brute fact. It is determined by the relevant concepts. And where illusions of sense are concerned, there are always relevant concepts: there are always relevant intentions about which concepts are being exercised. So reflection on those concepts is required to recognize the illusions as illusions. That is, reflection on those concepts is required to recognize that, at least as far as they go, no meaning has so far been given to these signs. $^{65}$

Someone might say, 'This is all very well. But you have still not explained how it can be appropriate to express such recognition - the recognition that something is a mere illusion of sense - by using, rather than mentioning, the relevant signs. Why is it not just as nonsensical to say, "There is no such thing as its being five o'clock at the North Pole" as it would be to say, "There is no such things as its being frumptiliously quirxaceous"?'

A number of (mutually incompatible) responses suggest themselves. $^{66}$

First response: The reason why it is appropriate to express the recognition that something is a mere illusion of sense by using the relevant signs, rather than mentioning them, is that what is recognized is parasitic on the illusion. If I say, 'There is no such thing as its being five o'clock at the North Pole', then I am doing something like what Gareth Evans would say I am doing when I make a singular negative existential statement: I am denying that there is anything that we understand when we have a certain

64. Cf. in this connection Percival (1993-94), p. 191.

65. Hacker (2000), pp. 365-367, is very pertinent here. I agree with much of what he says though I think that he is unfair to Diamond. See also Sorensen (2002), Section 7. This contains an account of 'the understanding of nonsense' - as a representation of an absence of meaning - which appears straightforwardly incompatible with the austere view. In fact, however, Sorensen is presupposing a context which makes what he is talking about something like the recognition of the illusion of sense that I am talking about. There is no (obvious) incompatibility with the austere view.

66. Cf. in what follows Baker and Hacker (1980), p. 480. Cf. also Anscombe (1971), pp. 85-86. 
illusion of understanding, and I am identifying the illusion by re-creating it. You cannot understand what I am saying without 'entering into' the illusion. ${ }^{67}$

Second response: It is not appropriate to express the recognition that something is a mere illusion of sense by using, rather than mentioning, the relevant signs. But nor, contrary to appearances, do we do that. If I say, 'There is no such thing as its being five o'clock at the North Pole,' then I am mentioning, not using, the expression 'five o'clock at the North Pole'-just as, if I say, 'By 1857 she had become George Eliot,' then, despite the surface grammar of what I say, I am mentioning, not using, the name 'George Eliot'.

Third response: It is indeed as nonsensical to say, 'There is no such thing as its being five o'clock at the North Pole' as it would be to say, 'There is no such thing as its being frumptiliously quirxaceous.' But this is still the best we can do when trying to express our recognition of that illusion - the point being that our recognition of that illusion, as of any other similar illusion, is incapable of being expressed. It is of a piece with the ineffable understanding afforded by the Tractatus.

I shall not try to arbitrate between these responses. Nor shall I speculate on what others may be available. I shall simply record (what may come as a surprise) that I am uncomfortable with the third. I find the postulation of that link between ineffability and nonsense overly crude. True, there is pressure on us elsewhere to say something along the same lines. Imagine that Henry is in the grip of this particular illusion and says, 'It is five o'clock at the North Pole.' Then a very natural way for us (to try) to register Henry's mistake is to say, 'Henry thinks that it is five o'clock at the North Pole.' Yet without some ancillary gloss, it would appear that the nonsensicality of Henry's assertion infects ours. ${ }^{68}$ This suggests that the best we can do to express our understanding of

67. Evans (1982), Ch. 10, esp. Section 10.4. (And see in particular pp. $344 \mathrm{ff}$. for the importance to Evans's account of our using, not mentioning, the relevant singular term.) Weiss, in Weiss (2001), expressly rejects any such application of Evans's ideas to this sort of case on the grounds that, where nonsense is concerned, there is no analogue of what Evans calls 'the game-to-reality shift': see Evans, op. cit., p. 362, and Weiss, op. cit., pp. $233 \mathrm{ff}$. But since, on Evans's view, the simple use of a nonreferring singular term itself issues in a kind of nonsense (Ch. 9 passim, e.g. p. 388), it seems to me that Weiss is in effect rejecting, not merely the application of Evans's ideas to this sort of case, but Evans's ideas themselves.

68. Cf. $T L P, 5.5422$. 
Henry - I do not, of course, say our understanding of Henry's assertion - is to produce nonsense, which in turn entails that our understanding of Henry is ineffable. ${ }^{69}$ However, I think it would be very rash to accede to this without further ado. It is not at all clear to me that we cannot make room for the straightforward truth of an assertion of 'Henry thinks that it is five o'clock at the North Pole,' perhaps along the lines of the second response above. (It is not at all clear to me, for that matter, that we cannot make some room for the straightforward truth of an assertion, in simple exegetical mode, of 'Wittgenstein holds that objects are simple.' Indeed, it is not at all clear to me-though this raises additional complications - that we cannot make some room for the straightforward falsity of an assertion, in simple exegetical mode, of 'Wittgenstein holds that facts are simple.')

I recoil from the third response, then. Nevertheless I do ultimately want to endorse something of that sort.

The discussion above is focused on one particular, rather superficial illusion of sense. But suppose we turn our attention to an altogether more fundamental family of illusions to which we are subject. I have in mind illusions that manifest the urge we have, itself ill-conceived, to transcend our limitations: illusions that arise when we try to apply concepts that are adapted to these limitations as though they were not, indeed as though they were not adapted to any limitations at all. An example, I suggest, is the illusion that attaches to the sentence 'The world exists as a limited whole. ${ }^{70}$

Consider the understanding which someone might have of this general phenomenon, and the associated capacity to recognize the illusions in this family as illusions. Can that understanding be expressed? Will not the attempt to express it involve producing more of the very nonsense in question? Will it not involve trying to transcend the relevant limitations in an effort to stake off the

69. There is something very like this train of thought in Diamond (2000), Section 4 and p. 161, though Diamond does not herself talk in terms of ineffable understanding, and I am closer to her than the remarks which I am about to make in the main text suggest. Cf. also Sorensen (2002), p. 173, where he writes, 'I can think you have a [particular] meaningless thought only if I think I have the same meaningless thought.' (Sorensen, who is arguing for the possibility of meaningless thought, sees this conditional as apt for an application of modus ponens. Others might see it as apt for an application of modus tollens.)

70. Cf. fn. 57. Cf. also, in connection with this particular illusion, Plato (1961), 144e145a; Kant (1998), A503-505/B531-533; TLP, 6.45; and Murdoch (1993), p. 1. 
territory that is home to the illusions; and perhaps also trying to implement some form of transcendental idealism whereby we cannot talk about anything that is not part of 'our' world, a world that is itself in some mysterious way bound by these limitations? In sum, will it not involve trying 'to draw a limit to thought' - where this is something that cannot be done unless 'both sides of the limit [are] thinkable'?

I ask these questions rhetorically. I realize that much more would be required to demonstrate that they have the answers implicit in my asking them. But if they do, then surely they provide a fair characterization of the project of the Tractatus. The illusions of sense in question are both the target of the book and the content of the book, and we, the readers, are supposed to understand the project-are supposed to understand Wittgenstein-by discovering that we cannot in the end make sense of the book. It falls apart in our hands. The very process of watching it fall apart is what brings us to our understanding of how these illusions arise, ${ }^{72}$ an understanding which, if the closest we can come to expressing it is producing just such nonsense, is ineffable.

To the extent that we achieve this understanding, we have, as I put it earlier, a command of the nonsense. We know how not to use the relevant concepts, as well as how to use them. And our grasp of those concepts is thereby fuller than it would have been had we not been tempted to extend them in this way and had we only ever had the latter knowledge. ${ }^{73} \mathrm{We}$ are masters of a technique: the practice of doing what Wittgenstein characterizes as philosophy. This is an activity rather than a body of doctrine. ${ }^{74}$ And our mastery is ineffable.

71. $T L P$, p. 3.

72. Cf. Crary (2000), p. 13. (It is tempting to say that, just as a proposition shows its sense-TLP, $4.022-$ so too a piece of nonsense shows its lack of sense. Cf. Conant (1989), fn. 39, where he writes, 'The only thing [nonsensical] propositions can show ... [is] their nonsensicality.' In fact, however, this is just more nonsense.)

73. Cf. Lear's comment in Lear (1984), p. 240: 'Post-neurotic consciousness is fundamentally more complex than a healthy consciousness that has never suffered disease or cure.' There is also a Biblical echo here: see Genesis, Ch. II, vv. 16-17, and Ch. III, vv. 2-5.

74. $T L P, 4.111-4.116$. (Wittgenstein talks of philosophy as aiming at the clarification of thoughts: 4.112. I take it that the clarification of thoughts includes the elimination, where necessary by re-casting the thoughts, of associated impulses to nonsense: e.g. 4.115; cf. 3.323-3.325. This is all connected with the powerful conception of thought that the Tractatus engenders, whereby what can be thought at all can be thought with complete clarity: 4.116.) The phrase 'masters of a technique' is a deliberate allusion to Wittgenstein (1974), Pt I, Sections 150 and 199. 
It seems to me, then, that we can say all of the following about the Tractatus:

- that it is written to convey something ineffable;

- that what it consists of, for the most part, is what would result from a (necessarily forlorn) attempt to express what it is written to convey;

hence

- that what it consists of, for the most part, is nonsense;

- that the reader is supposed to grasp what it conveys by processing this nonsense, and in particular by eventually recognizing it as nonsense;

- that recognizing this nonsense as nonsense means recognizing it as sheer lack of sense which says nothing about how things are;

and finally

- that not only is grasping what the book conveys supposed to be quite compatible with, it is supposed to demand, utter impatience with the idea of ineffable thoughts, or ineffable truths.

Whether this is more in line with the traditional reading or the new reading - whether, perhaps, it is more in line with something intermediate à la McGinn (see above, Section V) - I shall leave to others who may be interested in the question to judge. ${ }^{75}$

\section{REFERENCES}

Alston, William P. 1956. 'Ineffability', Philosophical Review 65, pp. 506-522.

Angene, Lyle E. 1982. 'Five O'Clock Here', Analysis 42, pp. 78-79.

Anscombe, G.E.M. 1971. An Introduction to Wittgenstein's Tractatus, Bristol: Thoemmes Press.

Baker, G.P. and Hacker, P.M.S. 1980. Wittgenstein: Understanding and Meaning, Volume I of An Analytical Commentary on the Philosophical Investigations, Oxford: Basil Blackwell.

Cavell, Stanley. 1979. The Claim of Reason, Oxford: Oxford University Press.

Conant, James. 1989. 'Must We Show What We Cannot Say?', in Richard Fleming and Michael Payne (eds.), The Senses of Stanley Cavell, Lewisburg: Bucknell University Press, pp. 242-283.

Conant, James. 1991. 'The Search for Logically Alien Thought: Descartes, Kant, Frege, and the Tractatus', Philosophical Topics 20, pp. 115-180.

75. I am very grateful to Jane Heal, Julie Jack, Marie McGinn, Howard Robinson, and Peter Sullivan for comments that helped me to improve this essay. 
Conant, James. 2000. 'Elucidation and Nonsense in Frege and Early Wittgenstein', in Alice Crary and Rupert Read (eds.), The New Wittgenstein, London: Routledge, pp. 174-217.

Cooper, David E. 1991. 'Ineffability', Proceedings of the Aristotelian Society Supp. Vol. 65, pp. 1-15.

Crary, Alice. 2000. 'Introduction', in Alice Crary and Rupert Read (eds.), The New Wittgenstein, London: Routledge, pp. 1-18.

Davidson, Donald. 1984. 'On the Very Idea of a Conceptual Scheme', reprinted in his Inquiries into Truth and Interpretation, Oxford: Oxford University Press, pp. 183-198.

Diamond, Cora. 1991. 'Throwing Away the Ladder: How to Read the Tractatus', reprinted in her The Realistic Spirit: Wittgenstein, Philosophy, and the Mind, Cambridge, Mass.: The MIT Press, pp. 179-204.

Diamond, Cora. 2000. 'Ethics, Imagination and the Method of Wittgenstein's Tractatus', reprinted in Alice Crary and Rupert Read (eds), The New Wittgenstein, London: Routledge, pp. 149-173.

Evans, Gareth. 1982. The Varieties of Reference, ed. John McDowell, Oxford: Oxford University Press.

Fitch, F.B. 1963. 'A Logical Analysis of Some Value Concepts', Journal of Symbolic Logic 28, pp. 135-142.

Friedlander, Eli. 2001. Signs of Sense: Reading Wittgenstein's Tractatus, Cambridge, Mass: Harvard University Press.

Grice, H.P. 1967. 'Meaning', reprinted in P.F. Strawson (ed.), Philosophical Logic, Oxford: Oxford University Press, pp. 39-48.

Hacker, P.M.S. 1986. Insight and Illusion: Themes in the Philosophy of Wittgenstein, revised edn., Oxford: Oxford University Press.

Hacker, P.M.S. 1996. Wittgenstein's Place in Twentieth-Century Analytic Philosophy, Oxford: Basil Blackwell.

Hacker, P.M.S. 2000. 'Was he Trying to Whistle it?', in Alice Crary and Rupert Read (eds.), The New Wittgenstein, London: Routledge, pp. 353-388.

Hofstadter, Douglas R. 1980. Gödel, Escher, Bach: An Eternal Golden Braid, Harmondsworth: Penguin.

Horwich, Paul. 1990. Truth, Oxford: Basil Blackwell.

Kant, Immanuel. 1998. Critique of Pure Reason, trans. and ed. Paul Guyer and Allen W. Wood, Cambridge: Cambridge University Press.

Koethe, John. 2002. 'Stanley and Williamson on Knowing How', The Journal of Philosophy 99, pp. 325-328.

Kremer, Michael. 2001. 'The Purpose of Tractarian Nonsense', Noûs 35, pp. 3973.

Lear, Jonathan. 1984. 'The Disappearing "We", Proceedings of the Aristotelian Society Supp. Vol. 58, pp. 219-242.

Lewis, David. 1986. On the Plurality of Worlds, Oxford: Basil Blackwell.

Mackie, J.L. 1981. 'Five O'Clock on the Sun', Analysis 41, pp. 113-144.

McGinn, Marie. 1999. 'Between Metaphysics and Nonsense: Elucidation in Wittgenstein's Tractatus', The Philosophical Quarterly 49, pp. 491-513.

Moore, A.W. 1984. 'Possible Worlds and Diagonalization', Analysis 44, pp. 2122.

Moore, A.W. 1989-90. 'A Problem for Intuitionism: The Apparent Possibility of Performing Infinitely Many Tasks in a Finite Time', Proceedings of the Aristotelian Society 90, pp. 17-34.

Moore, A.W. 1997. Points of View, Oxford: Oxford University Press.

Moore, A.W. 2003. 'Ineffability and Religion', European Journal of Philosophy 11. 
Murdoch, Iris. 1993. Metaphysics as a Guide to Morals. Harmondsworth: Penguin.

Percival, Philip. 1993-4. 'Absolute Truth', Proceedings of the Aristotelian Society 94, pp. 189-213.

Plato. 1961. Parmenides, trans. F.M. Cornford, in Edith Hamilton and Huntington Cairns (eds.), The Collected Dialogues of Plato, Princeton: Princeton University Press.

Proops, Ian. 2001. 'The New Wittgenstein: A Critique', European Journal of Philosophy 9, pp. 375-404.

Quine, W.V. 1992. Pursuit of Truth, revised edn., Cambridge, Mass.: Harvard University Press.

Ramsey, F.P. 1931. 'General Propositions and Causality', in R.B. Braithwaite (ed.), F.P. Ramsey: The Foundations of Mathematics, London: Routledge and Kegan Paul, pp. 137-255.

Reid, Lynette. 1998. 'Wittgenstein's Ladder: The Tractatus and Nonsense', Philosophical Investigations 21, pp. 97-151.

Schiffer, Stephen. 2002. 'Amazing Knowledge', The Journal of Philosophy 99, pp. 200-202.

Sorensen, Roy A. 2002. 'Meaningless Beliefs and Mates's Problem', American Philosophical Quarterly 39, pp. 169-182.

Stanley, Jason and Williamson, Timothy. 2001. 'Knowing How', The Journal of Philosophy 98, pp. 411-444.

Sullivan, Peter M. 1999-2000. 'The Totality of Facts', Proceedings of the Aristotelian Society 100, pp. 175-192.

Sullivan, Peter M. 2002. 'On Trying to be Resolute: A Response to Kremer on the Tractatus', European Journal of Philosophy 10, pp. 43-78.

Weiss, Jonathan. 2001. 'Illusions of Sense in the Tractatus: Wittgenstein and Imaginative Understanding', in Philosophical Investigations 24 (2001), pp. 228-245.

Wiggins, David. 1995. 'Categorical Requirements: Kant and Hume on the Idea of Duty', in Rosalind Hursthouse, Gavin Lawrence, and Warren Quinn (eds.), Virtues and Reasons: Philippa Foot and Moral Theory, Oxford: Oxford University Press, pp. 297-330.

Witherspoon, Edward. 2000. 'Conceptions of Nonsense in Carnap and Wittgenstein', in Alice Crary and Rupert Read (eds.), The New Wittgenstein, London: Routledge, pp. 315-349.

Wittgenstein, Ludwig. 1961. Tractatus Logico-Philosophicus, trans. D.F. Pears and B.F. McGuiness, London: Routledge and Kegan Paul.

Wittgenstein, Ludwig. 1974. Philosophical Investigations, trans. G.E.M. Anscombe, revised edn., Oxford: Basil Blackwell.

Wittgenstein, Ludwig. 1980. Culture and Value, ed. G.H. von Wright with Heikki Nyman and trans. Peter Winch, Oxford: Basil Blackwell.

Wright, Crispin. 1992. Truth and Objectivity, Cambridge, Mass.: Harvard University Press. 